\section{Culture, Perception/Belief about Death and their Implication to the Awareness and Control of the Socio-Economic, Environmental and Health Factors Surrounding Lower Life Expectancy in Nigeria}

\section{Abstract}

Death is not a new phenomenon in the history of humanity however, what matters is the perception about it among every population and their attitude towards the socio-economic, environmental and health factors surrounding it. The present paper focuses on examining the concept of death across generations and the religiously and culturally informed attitude and belief towards it; the implication of this to the knowledge about and control of the socio-economic, environmental and Health factors surrounding life expectancy in traditional African societies such as Nigeria. The paper with regard to physical explanations of the factors surrounding lower life expectancy among the traditional African people such as Nigerians bring to limelight the implication of superstitious belief about death to the awareness and control of the socio-economic, environmental and health factors surrounding lower life expectancy among the population.

Keywords: Death; Culture; Belief; Attitude; Environment; Health; Religion Africa; Nigeria
Okafor Samuel Okechi*

Department of Sociology and Anthropology,

University of Nigeria, Nsukka, Nigeria

*Corresponding author:
Okafor Samuel Okechi

samuelokey200@gmail.com

Department of Sociology and Anthropology, University of Nigeria, Nsukka, Nigeria.

Tel: +2348034853595

Citation: Okechi OS (2017) Culture, Perception/Belief about Death and their Implication to the Awareness and Control of the Socio-Economic, Environmental and Health Factors Surrounding Lower Life Expectancy in Nigeria. Acta Psychopathol. Vol. 3 No. 5: 56.

Received: July 14, 2017; Accepted: August 24, 2017; Published: September 01, 2017

\section{Introduction}

Although life is inevitably subject to termination and demise, there are still differences in the way individuals and groups perceive the end of it [1]. The differences in the perception of death by individuals and groups runs on different understanding of life itself such as life being seen from the religious perspective, cultural perspective as well as scientific perspective. While interpreting life scientifically may result in preparing for death based on doctor's report and other scientific evidence, those who see death from religious perspective are more or less interested in the religious injunctions about death, those who are perceiving death from the cultural end of the pendulum consider other factors which can be responsible for someone's death. These factors include the enemies who use spiritual powers to cause misfortune, the deities that can strike people if they offend the gods and other spiritually connected forces, which can end human life. As most religions offer a framework to answer existential questions concerning death and dying, individuals' attitude and belief towards death and dying can be tracing element towards the impression some people and groups have in the face of death beyond the socio-economic and cultural factors which may affect one's conception about the phenomenon [2]. While religion, socio-psychological and economic factors play roles in explaining individuals and groups' perception about finitude, age differentiation also affect the interpretation people give to human demise.

The role of religious belief and age differentiation has been pointed the manner in which people manage the issue of death as a phenomenon [3]. In essence, religion and age of individuals is a significant factor in the understanding of the way people perceive and react to death and the end of life. According to Jung, individual differences in age and life experiences also affect their perception about death. Furthermore, as death is naturally occurring and demands a retiring formality from humans, religion helps to abate the anxieties, which are bound to overwhelm the individuals who may likely see death as unacceptable.

Similarly, Frank [4] maintained that the inevitability nature of death made it a somewhat challenge to the perception and understanding of the individuals that the end up in search of consolation. According to Frank, spiritual belief and the level of 
civilization an individual had attained can significantly affect the understanding perspective one may have about death.

The way death is perceived in Africa in general and among the young ones is unique compared to other parts of the world [5]. Viewing death in the African perspective, only the elders are assumed to have finished their assignment on earth and can be perceived as due to go home to their ancestors; anything beyond that is the hand work of the enemy thus, if a young person dies it is naturally unacceptable.

According to Spilka et al. [6]; Becker [7], more than anything death is such a great wave of anxiety and concern to humanity even though a lot of explanations by man have been put in place via religion, culture and conventional science.

What makes a difference in the inevitability of death is usually the belief and attitude towards it. Among different societies of the world, how, when, where and what can cause death had become a source of concern to individuals, groups and even specialists such as Psychologists, Sociologists, Social workers etc., world over. There is evidence that divergence in culture, life experience and civilization can significantly affect the way individuals and groups can perceive death and dying [8].

Among most advanced nations, individuals have come to see death as part and a stage in life, which we can come to, irrespective of context and time. For instance, a survey by the Irish Hospice Foundation, revealed that among the Irish people, about $14 \%$ of Irish adults had written up an advance directives or living will, which by implication is an order to terminate their life if they face with terminal illness [8].

At some point, most Europeans and Americans also have come to the understanding that death is a necessary end which needs preparation by every individual based on their values and beliefs for example, recently, certain European nations have legally approved doctors assisted suicide and individual approval for life termination should one be faced with a severe health complication [9].

Among the civilized and advanced nations, the knowledge and beliefs about death and dying had moved from primitive, modern to post modernity. For example, it is now a well understandable view among some individuals and groups that dead bodies can be preserved in the hope of resuscitation when the science will improve in future [10]. Of paramount importance, here is the fact that attitude and belief people show towards death have much to do with culture, religion, level of education, socio-psychological and economic factors $[4,11]$.

In their work, Solomon et al. unravelled the psychodynamic processes underlying death and its awareness by the people of different religious backgrounds. According to Becker [7], morality affects the way people manage the terror associated with death such as relying on cultural worldviews and religious interpretations. Beck [3] in like manner with Jung in 1965, maintained that religious adherence contribute as a factor in ameliorating the impact of death on the feelings of the individuals about death. Explanation of death in both theoretical and conceptual framework is still a subject to the understanding of religiosity and cultural perspective among the population in any given setting even though some scholars seem to ignore these [12-14].

Similarly, some scholars have given more attention to anxiety about death more than other socio-psychological and cultural factors surrounding attitude and belief about death [15].

According to the study by Weafer [8], individuals in advanced nations such as Ireland, Belgium, Norway and Luxemburg were found to have civilized to make decision in advance about life termination should they face with terminal illness in future time. In a multiple city/nations, Weafer [8] discovered that majority of the respondents (82\%) preferred allowing their families and the doctor to make decision over termination of their life in the face of complicated terminal illness but have already recorded such in their advance directives. The above findings are in support of other studies such as the one by Irish Council for Bioethics' Survey, which found that $72 \%$ of respondents stated that they would prefer their next of kin to make healthcare decision on behalf of them, if they were incapable of doing so.

The belief and attitude towards death in most advanced nations are guided by knowledge/civilization. However, in many nations of Africa (Nigeria included), people still perceive death and dying in a different manner. This perception has religious, cultural and socio-psychological undertones. As was recorded by Umoh [5], the rate at which people ignorantly respond to the issue of the so call untimely death is becoming an instrument of social upheaval and violent crime among the rural dwellers in Africa and Nigeria in particular. This stems from the assumption that when a person die in the age category classified as untimely death, someone must have killed the person.

Specifically, the present paper is focused on the explanation of the relationship between culture and attitude towards death in Nigerian setting and their implication to the awareness and control of the socio-economic, environmental and health factors surrounding lower life expectancy.

The attitude towards death is the function of the individual psychological development which dependent on the level of social development among a group. A group that are less developed and are lagging behind in the current scientific understanding of the social and physical phenomenon around them are more likely to be vulnerable to primitive belief and culturally informed attitude towards phenomenon around them. A situation of this nature automatically results to the individuals and group living under the mercy of problems and challenges, which have been conquered by scientific advancement.

Awareness about the prevailing circumstance around the concept of death is the function of the liberation of the human psychology from the dominance of cultural belief and underdevelopment of the mind, which are responsible for stagnation in human imaginations and understanding. Currently, the extent of the dominance of the cultural belief and underdevelopment of the human psychology among the third world nations such as Nigeria is a hindrance to the enlightenment of the individuals and awareness creation on some important issues that are scientifically observable and controllable among the population. 
The prevailing socio economic, health and environmental factors surrounding death cannot be deleted because of ignorance of them instead, they will be increased as far as people may not understand them and objectively approach them. They are the inalienable part of the on-going social system of the society and will continue as far as the society continue in existence therefore creating an awareness for the general enlightenment about them will be the ultimate move to save the situation. On this note, the present work has as its objective, explaining the factors behind the attitude to death among the Nigerians; the implication of these to the factors surrounding life expectancy in the nation; and to bring to the lime light, the prevailing situation, which the ignorance about the factors surrounding death has caused in Nigerian context.

\section{Literature Overview}

\section{The concept of death and dying: cross examination across time}

Death is the cessation of life while dying is the process that ends in death. Dying is a process, which starts as gradual psychological withdrawal triggered by the biological system because of illness, sudden deformation of the entire system or vital part of the system or, natural termination of the life span of the human body because of old age; and ends in death [16].

Since the appearance of man on earth, there is nothing overwhelming as death as a phenomenon in human thinking. This in essence has informed the attitude the belief and perspective, which man show towards death [7]. Among other things, religion and culture have appeared as the escape root for man to understand and conquer death anxiety at least, since it is not possible to eliminate death by man.

However, due to the complexity of human cultures, different modes of religious beliefs and psycho-social differences, reliability of the religion and attitude towards death, cannot solely explain issues of the individual belief towards death and dying $[7,15]$. Inevitably, everyone dies, it is simple and inescapable hence the argument about death and dying and man's effort towards reducing the emotional and physical pains associated with them.

Historically, Aries gave a sketch of the stages and extents to which death and dying had reached as a phenomenon in human society. According to Aries, there had been numerous conceptualizations of death and dying right from earliest times to the present. Among them are, time death, this dates from the earliest times when death was an ever present reality and could be expected at any time. Death was less about the person than about the community. It was fame in the sense that it was spoken about and recognized.

Another one was death of the self, which is a form of death that developed in the late medieval period and was the beginning of awareness that death was individual. Remote or imminent death refers to death in the seventeenth and eighteenth centuries, when religion was in decline and scientific, rational thought on the increase. Aries refers to this period as the dumping of the tide in attitude to death. Death was now lonely and associated with separation.
In the analysis of Aries, death of the other was the new romantic version of death, which emerged in novels, and the idea of people being reunited in after life became fashionable in the nineteenth century. Finally, in Aries's analysis, invisible death is the contemporary form of death in western society. It is isolated; take place in a hospital where it is hidden and invisible.

Elias [17] provided an overview of changes in dying. According to Elias, our attitude to death fits into an overall changes in the society, which he termed the civilizing process. This process includes the development of restraint over all forms of extreme behaviours and feelings. Death which is likely to promote strong emotions is screened off as a way of limiting potential emotionally laden behaviours. As death is now, it is much less likely for the young, instead becoming a remote occurrence, the dying are also pushed further behind the screens, are isolated. Aries and Elias agree on the move to an isolated and invisible death.

Meanwhile in modern time, death seems to give people the chance to die serenely and calm by comparing to the past when people died in torment and pain [18]. Kellehear [19] argues that there is a model of good death, which people aspire to in contemporary times especially, in Western societies. This provides the framework within which family and professionals as well as the dying person seek to arrange for death. These arrangements include: (1) The doctor makes it clear to the patients that they are going to die, and this is accepted by the patient; (2) The person is able to sort out financial and personal issues with those around them; and (3) The person is able to continue working until later on.

Kellar demonstrated how these components of a good death reflect contemporary social values, including a belief in modern medicine and sciences, the need to care for one's family and the moral value of working. Thus, the assumed correct patterns of death and dying are in connection to the value of the society and are as much social as well biological, people do not simply die; they die in socially and biologically interpretable ways [20].

\section{Concept of death and fear about death}

The scientific study of death has been in place for centuries making it one of the phenomenon that have drawn the attention of researchers however, the attention in the study of death has been much on the fear and anxiety about death exhibited by the individual [21,22]. Freud was among the first scholars that first articulated the distinction between fear and anxiety especially as it is related to death. Primarily, fear is defined as a reaction to specific stimulus and anxiety, as can be exhibited by those suffering from neurosis [16]. Earlier studies such as the one by Drolet [23] and Batson [24] on death, religion as a comfort zone and fear of uncertainties; the sources of the two phenomenon were jointly treated for more comprehensive result. Among other things, they examined generally, the concept of death and anxiety, fear about death, fear of dying and other related types of fears in the same framework. Another study by Florian and Mikulincer [25], applied a more multidimensional framework of analyzing death anxiety involving the cultural, religious, conventional science as they are connected to fear, anxiety and doubt about death. Writing earlier, Tillich [16], has defined personal death anxiety (or 
individual peculiar anxiety towards death) as part of awareness of life finitude which trigger other reactions and concerns in individual life. Earlier studies to unravel individual interpretation of death and concern about death focused on death concern (i.e. frequently thinking about personal death).

In the late 90's, researchers such as Abdel-Khalek [26]; Maltby and Day [27] focused on the evaluation of how deaths overwhelmingly occupy the thought individuals in their daily activities. According to some findings following, the adoption of multidimensional framework, death obsessions, also correlates positively with death anxiety. Furthermore, death concern, depression and death anxiety, were dictated to be connected to personal death. Though overwhelming and interesting, the aforementioned findings were contradicted by a study carried out by Abdel-Khalek [28], who indicated a particular factor called "death distress" which according to him, operates as a spurious factor between personal death, death obsession, death depression, and death anxiety.

In the perspective of Terror Management Theory (TMT), death as inevitable phenomenon is one of the factors that terrify man that almost every aspect of man's life is an indirect effort to control or ameliorate the fear about it [29].

In direct comparison of the effect of death anxiety on individual psycho-social activities, using an ordinal scale ranking, Mager and Cabe, Abdel-Khatek and Al-Sabwah discovered that the individuals with higher level of death anxiety are less likely to find humour and satisfaction compared to their less anxious counterparts. Contrary to the above researches and explanation about death anxieties, attitude towards death is can be positive, as there are still differences among individuals, religious beliefs, cultures and socio-economic conditions that can affect attitude towards death. Working on the positive perspective about death, Wong et al. [30] maintained that individuals could accept death in a positive manner irrespective of time and circumstances surrounding it. More so, curiosity about death could be tallied with preparation for demise and joy about rest based on religious doctrine and cultural beliefs [31].

Curiosity as psychological situation can be accompanied by positive emotional states such as joy and excitement and somehow lower levels of anxiety [32]. As was recorded by Seaton and Beammont, curious individuals are proactive in coping with life adversity and also draw satisfaction from learning, and exhibit relatively high levels of emotional intelligence.

According to Abdel-Khalek, irrespective of the fact that death related experience are terrifying and affects individual perception of the phenomenon, open and objective discussion about it can still help the individuals with anxiety problem to cope.

\section{Religion and attitude/belief towards death}

Some scholars such as Porter [33]; Socha [34] and Thorson [35] have tried to connect religion and the way people cope with concerns about death and dying. Specific in this connectivity between religion and the way individuals perceive death is the feeling of unforeseen circumstances that accompany death beyond the physical explanation.

According to De Dezutter [36] citing Jung major world religions teaches about death and preparation for it as part of the process of life. He maintained naturally, preparing for death is the beginning of the second half of life which religion can provide a psychological relief for the individuals. Similarly, Socha [34] citing Frank [4] was of the view that awareness about the end of life is such of powerful emotional wave which requires an encouragement from the psychologically relevant institutions such as religion to calm the individual and to inspire them to see death as normal and inevitable.

Terror Management Theory which builds on Becker's assertion that morality plays a great role in the way people cope with death suggests that people construct cultural world view in order to manage the terror engendered by the human awareness of death. In the view of Terror Management Theory, cultural worldviews including religiosity provide important paths for the understanding of life and the inevitability of death [3].

Given that numerous psychological theories have connected human concerns about death and dying with religiosity, attitude and perception about death seems relatively connected to the religious doctrine that overwhelm the individual. Even though substantial number of studies such as the ones by Gartner [14]; Hutsbaut [12]; Duriez [37]; Falkenhain and Handal [38] have touched the relationship between religiosity and death attitudes, these studies were not enough to have addressed comprehensively the issue of religion and death as acknowledged by Neimeyer et al. [1].

Perhaps because of these limitations, evidence for a link between religiosity and death anxiety is equivocal. For instance, contrary to the earlier notion that religion helps individual to cope with death anxiety, Feifel's [39] research showed that religiosity was negatively correlated with death and anxiety towards death. In yet another study subsequently, Feifel et al. [40] found a negative association between religiosity and death anxiety.

Christopher, Drummon, Jones, Marek and Therriault in their cross examination of death and religion adherence found that religiosity was positively related to what was classified as positive death such as death related to the failure of the human biological system. Specific here is that there conditions among the religion adherents which warrant death and as such should be accepted not only as a fate of someone however as spiritual call to rest. Together, these findings point to the importance of distinguishing between different deaths attitudes and more specifically, they point to the usefulness of focusing on both negative (anxiety and avoidance) and relatively more positive attitudes towards death (i.e. a neutral or even accepting orientation towards death). Although from the point of view of scholars whose their interest in studying death is overwhelmed by the terrifying aspect of death may more or less, focus on scales and frameworks which try to $x$-ray how fear and anxiety are related to death; there are still other framework of analysis which can extract information based on the benefits of death for individuals and groups hence studies based on the positive view about death. For larger framework of analysis and a somewhat comprehensive understanding of death, Goesser et al. [30] have expanded the concept of death and framework of study about attitude related to death. In the framework include, neutral acceptance, which according to them 
is the perception of death as inevitable. Acceptance, which is a positive outlook on death rooted in the belief in happiness after life with religious undertone. Escape acceptance, where death is a welcome alternative to a life full of pain and misery; fear of death, involving feelings of fear evoked by confrontations with death and death avoidance, involving avoidance of thinking or talking about death in order to reduce death anxiety.

A number of studies have tried to adopt descriptive measures of attitude to religion and involvement in religious activities e.g. Church attendance to test the relationship of religion to attitude to death. Some of these studies have revealed some hiding facts about religious attitudes as they are related to attitude to death. They have been found more closely related to profound difference in individuals' psychological functioning; this has shown a clearer pattern of associations with death attitudes. Cohen et al. [41] for instance, showed that religious adherents who adopt religion as part of their lives have shown negative attitude towards death anxiety. According to the findings by Ardelt and Koenig [42], whereas those who adopted religion as part of their lives showed favourable attitude towards accepting death, individuals who see religion as inessential showed favourable attitude towards death anxiety. Together, these studies support the usefulness of adapting a multidimensional approach to both religious attitude and death attitudes.

\section{Individual religious doctrine and perception about death}

As was recorded by Wulff [43], all approaches to religion can be categorized into two dimensions with focus on two axis. These include the inclusion versus exclusion of transcendence dimension (vertical axis), which specifies whether or not people belief in a transcendental reality. The literal versus symbolic dimension (horizontal axis) which indicates whether religion was interpreted literally or symbolically. Whereas in his own analysis the inclusion versus exclusion dimension pertains to religiosity as such, the literal versus symbolic dimension pertains to the way people perceive religious contents. From the two dimensions, four basic attitudes toward religion were derived $[12,43]$. These attitudes include: (1) Literal affirmation or orthodoxy (i.e. high on both inclusion versus exclusion and high on literal versus symbolic; (2) LITERAL disaffirmation or external critique (i.e. low or inclusion versus exclusion and high on literal versus symbolic); (3) Symbolic affirmation or second Naiveté (i.e. high on inclusion versus exclusion and low on literal versus symbolic); (4) Symbolic disaffirmation or relativism (i.e. low on both inclusion versus exclusion and literal versus symbolic).

Furthermore, in Wulff's analysis orthodoxy is typical of individuals defining themselves as religious and interpreting religious content in a rigid, close pointed, and dogmatic fashion. Individuals with an attitude of second Naiveté according to Wulff [43], also define themselves as religious persons yet process religious contents in a more symbolic, open and tolerant fashion. They assume that several interpretations of religious contents are possible and try to find an interpretation of religious content that they find personally meaningful. Individual with an attitude of external critique according to him reject the possibility of a religious reality based on strict and literal arguments by implication, making effort to link religious stories to empirical validation. Finally, in Wulff's analysis, people holding an attitude of relativism towards religion also define themselves as non-religious. They respect other people's choice to be religious but do not see strong attachment to religion as necessary but to find personal meaning in life via religion.

In line with the religious attitude scale developed by Wulff [43], Hutsebaut [12] developed the post-critical belief scale to measure the four religious attitudes developed. Similarly, Duriez and Hutsebaut [44] which have demonstrated the distinctiveness of the subscale developed by Hutsebaut developed throng factor analysis based on the post-critical belief scale. Theoretically, it has been reconfirmed that meaningful relations exist between the four attitudes and a number of external variables. For instance, religious attitudes expressing a more literal and dogmatic approach to religion have been shown to relate to higher authoritarianism [37], a normative self-protective approach to interpretation of phenomenon [45], more controlled reasons for engaging in religious activities [37].

Nevertheless, an important function of religion which therefore mentioned analysis triggered by Wulff [43] aims to bring to the fore in relation to perception about death is that religion deals with the potentially terrifying awareness that we will someday die [29].

Religion deals with the problem of death by providing a belief system that not only denies the very notion of death, via the promise of an afterlife but it also provides a strategy for living one's life in the here now.

In presenting the explanation of the functional capacity of religion on attitude towards death, there is every tendency to see such as trivial and simple however, other scholars have indicated that its dynamic can actually be complex [6]. One of the main factors that contribute to this complexity is that there are many different approaches to using religion such as intrinsic and extrinsic because of their consistent link to death attitudes [46]. Intrinsic orientation describes the use of religion, as a meaning endowing framework for which all life is understood [16, 47]. In view of Terror Management Theory, intrinsic orientation as a religious approach is not only relevant in understanding the factors behind less anxiety towards death however such is a connectivity between religion as a phenomenon and cultural worldview about death. A number of studies have shown the positive influence of intrinsic religiosity on coping with death anxiety [48].

Furthermore, another research has shown a positive relation between intrinsic religiosity and what is classified as high death anxiety [41]. Most studies that have examined the relation between intrinsic orientation and death anxiety, along with terror management theory, suggest that intrinsic orientation is associated with less death anxiety, especially on human imagination. They also suggest that individuals high in intrinsic orientation are more likely than those with lower levels of intrinsic orientation to approach the topic of death with anxiety because their religious beliefs buffer them from death related concerns $[22,28,49]$. Maltby and Day [27] showed that among 
protestant students, death obsession correlates negatively with intrinsic religiosity. Extrinsic orientation on the other hand, describes one's use of religion for self-serving and utilitarian. Unlike intrinsic orientation, extrinsic orientation treats religion in a superficial manner. According to research in connection to extrinsic orientation, the approach is positively associated with various manifestations of psychological distress such as depression, anxiety, stress reactivity and even death anxiety. These findings in connection with Terror management theory suggest that extrinsic orientation would not likely help discourage one's death anxiety.

According to Batson [24], quest orientation describes on honest approach to religion. Quest orientation is similar to intrinsic orientation in that it is based on a genuine approach to religion. Indeed religious orientation of individuals plays a role in their attitude and belief about death and the after math of death. This can be observed in Nigerian context among the Christians and even the Muslims who attach value to the belief about life after death hence, bearing the pains of death emotionally with the biblical verses where Christ has promised the Christians rest after here on earth.

\section{Culture and perception of death in traditional African societies}

Among the African traditional societies, death is attached with such sacredness such that it is becoming harder for people to see it as natural phenomenon other than human induced. This is becoming worst especially in the era when a lot of socio-economic is fuelling the low life expectancy and health factors in the African nations. In the understanding of majority of traditional African people, it is assumed or rather believed that death before certain age in life is unnatural and therefore is connected to invisible powers. According to Umoh [5] this attitude to death has done more harm than good to the families and households even communities where such attitude is dominant. In most societies in Africa especially in Nigeria rural communities, there is a lot of bitterness which is overtly or covertly shown after burial. In most cases, some individuals or even families have to avoid the burial scene reasons ranging from the fear of being accused to some people avoiding being bewitched at the arena. Out of fear, some people decide to leave the community during the burial to avoid trouble. In most cases, such deliberate avoidance is interpreted as tacit signs of guilt, and the houses and other personal belongings of such people are often destroyed.

As was recorded by Umoh [5], five persons were executed without trial in one of the rural communities in Nigeria in connection to the death of some persons and accusation of witchcraft. The attitude of Africans towards death in general and death when it involves younger people in particular is unique. Apart from the deaths of elders who are believed to have returned to their ancestral homeland after a ripe old age, all other deaths in Africa, especially in Nigeria are considered unnatural; they are viewed as premature, untimely, and therefore caused by an evil force.

In most African societies (Nigeria included), rejecting the possibility of people dying of a natural cause or death as inevitable is becoming the perfect way of coping psychologically with moment of grief. Without certifying in their subconscious mind that this is who or what killed their loved ones, the typical African society members find it difficult to accept death's inevitability. Consequently, since it is not easy to lay hand on any physical and reliable scientific explanation that can convince the bereaved especially with poor health system, the nearest argument becomes the witchcraft and spiritual enemies. In like manner as was recorded by Kofi, an illness, which does not yield to medicine, must be attributed to other baneful forces, ranging from the spiritual foes to the gods and deities. Furthermore, Kofi maintained that except in the death of a very old man, the Akan people of Ghana do not believe the natural inevitability of death as timeless.

Among the Anangs of Southern Nigeria, the names given to presumably incurable diseases project such diseases as unnatural and the handwork of an enemy or the gods. Due to the poor health system and lack of health information among the poor masses, there are a number of ailments, for instance, paralysis, epilepsy, elephantiasis etc., which according to popular belief, does not strike their victims naturally. Such diseases are always said to be inflicted upon one, or as they put locally, "given to victims by enemies".

According to Nnamani [50] spiritual beings have the power to influence human life positively or negatively in the context of African culture? On their own accord, or if incited by wicked people, they could inflict misfortune of a serious magnitude on people, ranging from physical and mental sickness to bareness, accidents, premature deaths, drought, poor harvest, unfulfilled life, and personal failures. The demons could implement the evil designs directly or indirectly through the agency of wicked persons.

As was summed by Umoh [5], the belief and attitude towards death and dying is a subject to experience from the environment and culture in which one lives. By implication, what people show as attitude towards death and dying is typically the reflection of his cultural background including religious belief. In African societies especially in Nigeria, belief and attitude towards death and dying is mostly related to cultural background, religious belief, and level of civilization.

\section{Culturally induced perception about death in contemporary Nigeria: the logic of longevity and economic importance of man}

The logic behind the perception of death among the majority of Nigerians cannot be far from the cultural interpretation of the actual time for acceptable death. The acceptable death among most cultural groups in the country is the common logic of utility and liability. While utility value or the expected utility value makes an individual viable and needful, the liability aspect of the person makes the person less needful or even unimportant. In the worldview of most societies across Nigeria, the issue of death is logically seen as the moment of disposing with the individuals when they have overstayed their usefulness in all ramification otherwise, there error somewhere. In essence, when somebody die at the middle of his life time usually counted on the basis of his capability and other socio-economic and psychological 
fitness, there is every sense of suspiciousness that someone or something has interfered with his life. This informs the degree at which the bereaved react to some categories of death. While death involving a young man at his productive age triggers a high degree anger and furiousness, which of an old man who barely does anything is with the feeling of sympathy. Likewise the death of an infant which is mostly viewed as ogbanje, abiku or danwabi. In any case, this situation is simply seen as the problem of the spirit world which ought to be treated so that the particular spirit child will not come back. Similarly, the husband and wife affected by such experience console themselves with the hope that when the real child comes he will stay especially if the family as a whole has by implication convinced that the woman married into their family is not barren. Even if there is suspicion that someone has caused the death of the infant, it cannot be felt with such bitterness like that of a young man who died at his productive age. In a somewhat likely scenario, when a man suffering from insanity for years dies even on the roadside, there may be no emotions over his death. Where a concern is raised about him that will simply be on the ground that he must be removed and buried so that his corpse does not cause epidemic. Per adventure he died in a forest or outside the city where people will rarely see the carcases or perceive the odour, the carcases may be allowed to decompose by itself at the place. All deaths are lost ideally but not all deaths that are lost pragmatically; this is because the gravity of death based on age, productivity and popularity of the individual determines the extent of emotions attach to it.

Following the belief that a child ought to contribute in the economic wellbeing of the family and by natural cause, is expected to live to old age when he may not be economically viable, the child is expected to live to old age. If the child eventually dies without fulfilling this expectation by the family members and other relations he becomes a lost. In effect, this arouse in the mind of the family members and loved ones, a form of bitterness.

Having believed that every child has come to the world to fulfil a mandate, which will only finish when he is very old, whenever death strikes at the middle of someone's life, it is interpreted as interruption. This in essence must have come from an enemy since the gods and the loved ones will always wish the innocent citizens long life and prosperity. On the contrary, having believed that everyone will outlive their usefulness before they can die, the acceptable death now becomes the death of someone who has become very old that he can no longer do anything. By implication, there is no specific age in the cultural context that any one is due to die except when the person has become physically, economically or psychologically unable. This goes with the interpretation given to people with deformity and terminal disease, which in any case, receive no serious attention. When someone is deformed or on terminal illness, there is an enemy somewhere or the gods has stricken that person in anger. In such a situation, when the person continues in that condition his importance is gradually fading away and if he eventually dies after some time the death may not be as grievous as the one involving someone who is healthy and economically viable. Although there may be emotional feelings for those with some level of deformity among the family members when they die, such feelings are simply emotional sentiment limited by what the individual can do. However, where there is nothing the individual can do entirely, their death will be preferred to life hence in such cases among the Igbo you will hear such word as odi ndu onwu ka mma (the one who is alive but would have been better off if he died). In such a situation, if death occurs it is simply seen as going to rest with the ancestors by the person. Indeed the grievances and other emotions attached to death are connected with the extent of relevance of the dead to the family, friends and community hence the degrees of deaths and bereavement. The diagram below summarizes the categories of deaths and the degree of bereavements among the traditional societies in Nigeria.

When death involves the most economically viable individuals at their productive stage it is never seen as natural phenomenon without the connection of spiritual forces even in the contemporary time. It is simply seen as a spiritual phenomenon, which no matter how it occurred is connected to spiritual cause. This is the reason for the different interpretations to death at different age categories. The children who died after their birth (infant mortality) are seen as spirits that have come to torment the mother and the family or because of the anger of the gods against the family that bears a curse. In this case, the family ought to seek for super natural intervention either to stop the particular child from coming or to break the curd of relationship between the child and the world of the spirit (Figure 1).

When a person die at the middle age (youthful death), even if it was accident, suicide, venereal disease etc., it will be explained via spiritual cause. In this case, the person may have committed abomination or the parents and even the community where he belong to may have committed sin, which attracted the wrath of the gods. In another explanation still connected to spiritual cause, it may likely be that an enemy by the corner has instigated the cause of the death spiritually.

When an elderly person dies and the person is still economically, physically and psychologically active, anything that cause the death must have come from spiritual cause. In this situation, it may have been because of the evil the person has done (nemesis) which people know or did not know about or an enemy somewhere who is not happy with the person. When an elderly man dies who is economically, physically and psychologically inactive, the ancestors have called him to rest. More importantly, if the person failed to die after some years of outliving his economic, physical and psychological viability, the family or people around will suspect him of belonging to witchcraft that may have extended his life so that he will continue to bewitch others.

\section{The Implication of Superstitious Belief about Death to the Awareness and Control of Socio-Economic and Health Factors Affecting Life Expectancy}

Knowledge about life expectancy and factors surrounding it is lacking among the traditional societies in Nigeria even in the contemporary time. For instance, it is an abomination to say that somebody may likely die at the middle of his life. Should anybody say such a thing, either he is wishing people death as messenger 


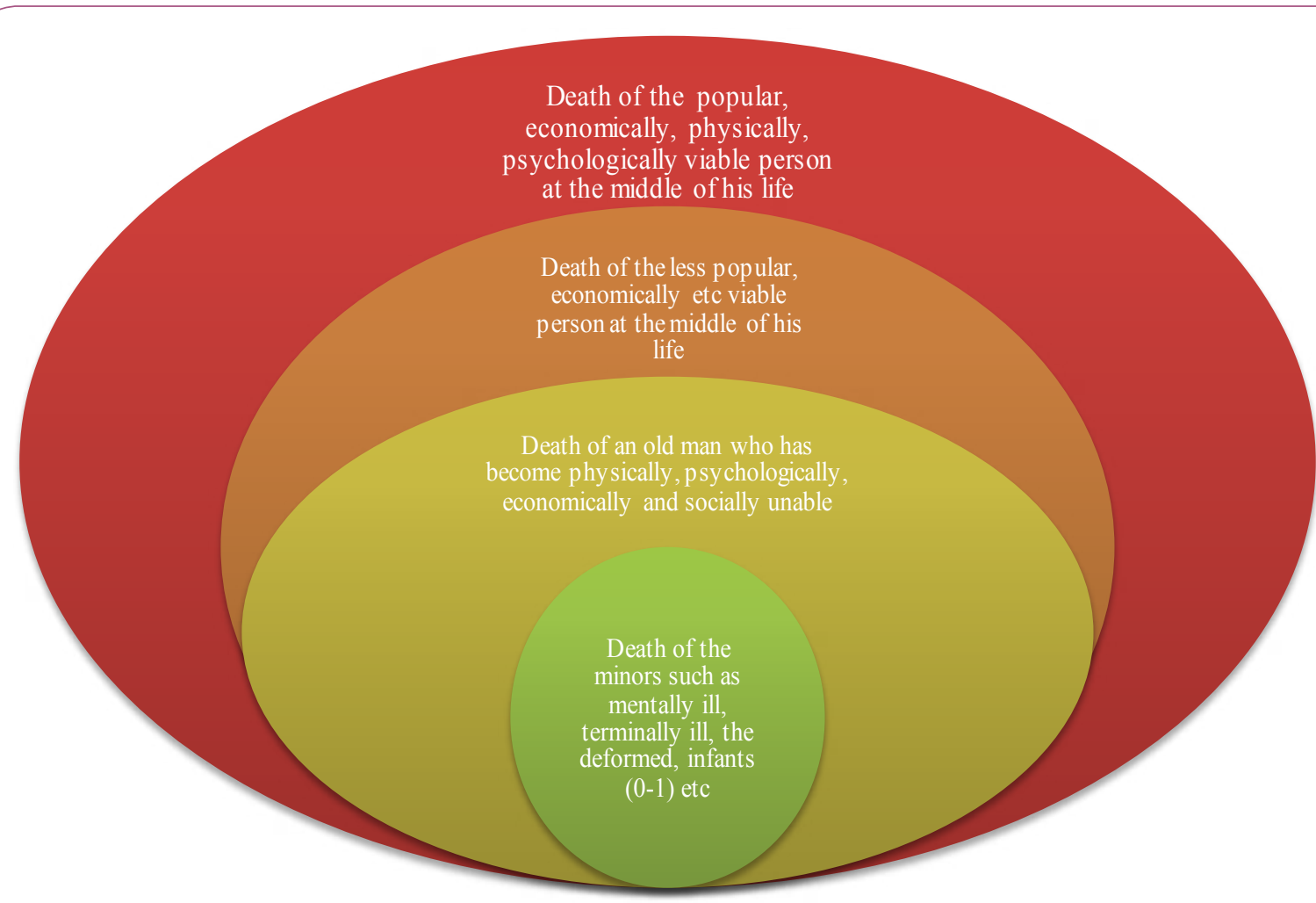

Figure 1

The diagrammatic representation of the categories of deaths and the gravity of bereavements attach to them in Nigerian traditional societies.

of doom or the person is mentally unfit. The only comment that is acceptable among the people is that everybody will live a long life hence, any preacher preaching about death will lose members, any government agency working on death related information may not receive proper attention, a researcher researching on death may not receive proper attention, etc.

Generally, information about factors surrounding death in this part of the world is very poor among the masses. This is because of the partially or non-functional health ministry in different parts of the country. Among other things, it is the responsibility of the health ministry enlighten the public about the realities of death as a natural phenomenon however, in the presence of corruption and mediocrity among the health workers, it is difficult for them to dully carry out their responsibilities on this aspect. Although individuals may read and know about things like death; Nigeria has not grown to such level of people understanding things like death objectively and approaches it as such. The poor masses still deserve the right to be enlightened on the issue of death as it relate to physical, health, social and cultural realities in order to unhook majority of the masses from culturally induced attitude towards the issue of death and dying. This is to help the masses understand the issue of life expectancy and health, socio-economic and socio-psychological factors surrounding the chances of people living and dying. Poor or lack of information about life expectancy among a population and factors surrounding such is a gateway to culturally induced interpretation of death, which in any case among the traditional societies in Nigeria is channelled towards spiritual phenomenon and enemies around.
Of paramount interest, here is the fact that instead of tracing the physical factors that are likely responsible for the death of someone among the population, the attention is focused on the spiritual enemies such as evil spirit, wicked neighbour, ancestral curse or provoking the anger of the gods. By implication, certain reoccurring diseases, behavioural factors, socio-economic factors that are engendering lower life expectancies or rather premature death are not given attention. For instance, many have died in the churches while waiting for spiritual cleansings, many have died in the shrine of some herbalists while waiting for spiritual intervention in sicknesses which have natural cause, many have died in hands of unqualified medical personnel and the family receive the consolation that there is an enemy somewhere who has manipulated the diseased. Certain diseases that survive in unhygienic environments have become mysterious elements living with the population without their knowledge about them or serious attention to such. Most of these diseases when they surface and strike someone, they are either treated haphazardly or not even recognized as naturally occurring disease which requires medical attention but enemy's handwork. Such diseases end up killing many because of poverty, lack of the knowledge about the disease, self-medication or lack of qualified medical personnel around. When such medical condition result to death, the first attention is on who has inflicted such a disease on the individual either the human enemies around or the deities.

I have witnessed several cases where unqualified nurses gave wrong injection and drugs to infants leading to their deaths yet, such unqualified medical personnel succeeded in convincing the families that the enemy from the village caused the death. 
Common malaria has killed many people while they were taking fake malaria drugs or wrong prescriptions and at the same time resigning to fate for the gods to avenge who ever that has inflicted the disease on them.

Beyond illness as one of the unseen factors responsible for lower life expectancy among the population, poor environmental hygiene plays a serious role in the factors that cause premature death and encourage lower life expectancy among Nigerians. Among the urban dwellers, offensive odour and stagnant water is a reliable indication that you have getting to the city. In confirmation of George Simmel's thesis, the Nigerian cities are adorned with heaps of dustbin, which stay some times for a long time before the removal or even remain permanently within the population.

Cleaning the drainage system is out of government priority and that of the inhabitant such that these drainage systems both on the street and in the compounds become a home for stagnant water and the inhabitation for all kinds of deadly microbes and mosquito (the agent of malaria). Again, poverty, low awareness of public health issues and behavioural risk factors still remain some of the salient factors in the lower life expectancy among the people but were ignored in the eyes of the people as they pursue superstitious belief about death and circumstances surrounding death. For instance, because of poverty numerous families cannot afford to eat decent food or take care of their health in a relatively good hospital or with effective drugs for proper treatment of an ailment.

Among the numerous inhabitants of the rural communities and even the cities in Nigeria, there is still low awareness of the implication of self-medication to their health. The most consulted place for treatment among the rural dweller and to some extent the urban dwellers is Chemists (drug vendors) who in most cases have no proper knowledge of health issues but interested in their profits. These people provide their client with drugs without Doctor's prescription or even a directive from medical lab test; they even go to the extent of treating complicated cases without any qualification to do so. Similarly, some depend on the street herbalists who carry concoctions mixed from all kinds of things for treatment of multiple ailments. On several occasions, many individuals have died because of these kinds of medical treatments of which their contractors diverted the attention to witchcrafts and enemies from the neighbourhood.

Risk-behavioural factors, which expose many individuals to premature death, are one of the ignored factors that had positively affected lower life expectancy among the population. Most people work in a threatening environment without considering the fact that the more they expose themselves to such environment the lower the chances of their living long. Many work in the industries where they inhale fine particles on hourly basis or even exposed to radioactive emission without protection. Some work in an environment that is very unhygienic to the extent that they inhale and romance with microbes and bacteria. Still, others work in a place where the chances for the occurrence of accident is very high, many more work in places where stress is the order of the day, etc. all these are factors that lower the life chances of the population however, they are totally ignored. The focus is always the spiritual attack that may have caused the accident, sickness or death.
Psychologically, when somebody dies the family members and the loved ones try to console themselves by narrowing the cause of the death to a particular suspect or group of suspects. In this situation, the family members and the loved ones will mark a particular family or individual as the suspected enemy and by so doing create a ground for potential conflict which may explode in future. When the family members have certified in their erroneous judgment sometimes, after consulting for divination, the next stage becomes how to avenge the death of their loved one who has died.

In Durkheimian parlance, to heal the wound as far as the suspected enemy has been named, the group concerned will now go in to plan on how to revenge. In some cases, there have been open confrontations with the suspected spiritual killer of the diseased or direct open extra judicial execution of some individuals suspected to be involved in the death of someone. If the deceased is a man and has married, the wife will be forced to remain isolated and do some diabolic things to certify that she knew nothing about the death of the husband. In some cases, dead bodies have been buried with weapons so that they will go after their killers. The beliefs about death among most traditional societies in Nigeria are more of spiritual than natural and therefore relegate the issue of the factors surrounding life expectancy to the background.

\section{Conclusion}

Death as a natural phenomenon is obtainable across human societies and generations making it one of the phenomenon human thinking and beliefs at least for now cannot change that. Human being can only think, imagine or belief something about death as a phenomenon but cannot change or stop its existence rather, human beings can only improve on the chances of longevity by looking at the socio-economic and health factors that surround life expectancy in a particular society or among a particular group. In the case of African traditional societies with special emphasis on Nigeria, superstitious belief has overtaken the proper knowledge about factors surrounding death and life expectancy. This of course has led to the situation of many illicit activities leading people to their untimely grave while the individuals and groups are chasing after shadow and causing unnecessary problems in the name of avenging the dead. Lack of knowledge about the socio-economic and health factors remain the unseen factor among the traditional African people such as Nigerians, which continue to threaten the improvement of life expectancy among the population and not the spiritual enemies based on culture or religion.

\section{References}

1 Neimeyer RA, Wittkowski J, Moser RP (2004) Psychological research on death attitudes: an overview and evaluation. Death Stud 28: 309-340.

2 Wulffs DG (1991) Understanding religion and life. J Relig Spiritual Aging 18: 93-110.

3 Beck R (2006) Defensive versus existential religion: is religious defensiveness predictive of world view defense? Pers Individ Dif 29 : 118-131. 
4 Frank VE (1977) Man's search for meaning: An introduction to logotherapy. London: Hodder \& Stroughton, p: 154.

5 https://dspace2.creighton.edu/xmlui/handle/10504/64306

6 Spilka B, Hood RW, Hunsberger B, Gorsuch R (2003) The psychology of religion: An empirical approach. New York: The Guilford Press, p: 636.

7 http://academyofideas.com/2016/09/the-denial-of-death-ernestbecker/

8 Weafer J (2009) A Qualitative study of public perceptions of end of life care. Dublin: The Irish Hospice foundation.

9 http://brewright.com/wp-content/uploads/2014/03/Wright-ZozulaWilcox-2012.pdf

10 Schmalleger WN (2014) Civilization and attitude to death and dying. Death Stud 28: 309-340.

11 Pyszczynski JR (1998) Socio economic status and attitude to religious activities. Polish Psychol Bull 44: 439-448.

12 Hutsebaut D (1996) Post critical belief: a new approach of the religious attitude problem. J Emp Theol 9: 48-66.

13 Kranise N (2011) Reported contact with the dead, religious involvement and death anxiety in late life. Rev Relig Res 52: 347-364.

14 Gartner J (1996) Religious commitment, mental health and pro social behaviour: a review of empirical Literature. Relig Clin Prac Psychol 10: $51-84$

15 Neimeyer RA, Wittkowski J, Moser RP (2004) Psychological research on death attitudes: an overview and evaluation. Death Stud 28: 309-340.

16 Piotrowski JP, Rozycka J, Piotrowska MA (2013) Association between death fascination, death anxiety and religion among polish college student. Polish Psychol Bull 44: 439-448.

17 https://monoskop.org/images/f/fc/Elias_Norbert_Loneliness_of_ the_Dying_2001.pdf

18 Lin AHMH (2003) factors related to attitudes toward Death among American and Chinese old adults. Omega J Death Dying 47: 3-23.

19 Kellehear A (1990) Dying of cancer: The final year of life. London: Harwood publishers, p: 246.

20 Haralambos M, Holborn M (2008) Sociology, themes and perspectives. Hammersmith: Harper Collins Publishers.

21 Yalom ID (1980) Existential psychotherapy. New York: Basic Books, p: 524.

22 Winkip J (2006) Who is afraid of death? Religiousness, spirituality and death anxiety in late adulthood. J Relig Spiritual Aging 18: 93-110.

23 Drolet J (1990) Transcending death during early adulthood: symbolic immortality, death anxiety and purpose in life. Clin Psychol 46: 148-160.

24 Batson CD (1976) Religion as prosocial: agent or double agent? J Sci Stud Relig 15: 29-45.

25 Florian V, Mikulincer M (1997) Fear of death and the judgment of social transgression: a multi-dimensional test of terror management theory. J Pers Soc Psychol 73: 369-380.

26 Abdel-Khalek AM (1998) The structure and measurement of death obsession. Personal Individ Differ 24: 159-165.

27 Maltby J, Day L (2000) Religious orientation and death obsession. J Genet Psychol 161: 122-124.

28 Abdel-Khalek AM (2004) A general factor of death distress in seven clinical and non-clinical groups. Death Stud 28: 889-898.
29 Solomon S, Greenberg J, Pyszzynski J (1991) A terror management theory of social behaviour: the psychological functions of selfesteem and cultural world views. Adv Exp Soc Psychol 24: 91-159.

30 Goesser G, Wong P, Reker G (1987) Death attitudes across life span. Omega J Death Dying 18: 113-128.

31 Piotrowska M, Piowtrowski J (2009) Death anxiety and fascination scale. Psychol Forum 14: 90-109.

32 Ben-Zur H (2002) Association of types of behaviour with the emotional traits of anger and curiosity. Anxiety, Stress \& Coping 15 95-104.

33 Porter B (2001) The catholic nation: religion, identity and the narratives of polish history. Slavic and East European Journal 45 : 289-299.

34 Socha P (1999) Ways religious orientations work. J Psychol Relig 9: 209-228.

35 Thorson JA (1998) Religion and anxiety: Which religion? Which anxiety? San Diego: Academic Press.

36 De Zutter J, Soenens B, Hutsebaut D (2006) Religiosity and mental health: a further exploration of the relative importance of religious behaviours versus religious altitudes. Personal Individ Differ 40: 807-818.

37 Duriez B (2002) Religiosity and conservatism revisted: relating a new religiosity measure to the two main conservative political ideologies. Psychol Rep 92: 533-539.

38 Falkenhain M, Handal P (2003) Religion, dealt attitudes and belief in after life in the elderly: untangling relationships. J Relig Health 42: 67-76.

39 Fiefel H (1990) Psychology and death: meaningful rediscovery. Am Psychol 45: 537-543.

40 Feifel H, Brans Comb A (1973) Who is afraid of death? J Abnormal Psychol 31: 38-45.

41 Cohen A, Pierce J, Chembers J, Mead R, Gorvine B, et al. (2005) Intrinsic and extrinsic religiosity, belief in after life, death anxiety and life satisfaction in young catholics and protestants. J Res Personal 39: $307-324$.

42 Ardelt M, Koenig C (2006) The role of religious for hospice patients and relatively older adults. Res Aging 28: 184-215.

43 Wulffs DG (1991) Understanding religion and life. Journal of Religion, Spirituality \& Aging 18: 93-110.

44 Duriez B, Hutsebaut (2000) The relation between religion and racism: the role of post-critical beliefs. Ment Health Relig Cult 3: 85-102.

45 Duriez B, Soenens B, Beyers W (2004) Personality, identity styles and religiosity: an integrative study among late adolescents in Flanders (Belgium). J Personal 31: 877-910.

46 Donahue JM (1985) Intrinsic and extrinsic religiousness: review and meta-analysis. J Pers Soc Psychol 48: 400-419.

47 Akport GW, Ross JM (1967) Personal religious orientation and prejudice. Pers Soc Psychol 5: 432-443.

48 Jonas E, Fisher P (2006) Terror management and religion: evidence that intrinsic religiousness mitigates worldview defense following mortality salience. J Pers Soc Psychol 91: 553-567.

49 Stack S (2002) Blues fans and suicide for honour. Death Stud 26: 431-437.

50 Nnamani A (2002) Demonology and African experience. Nacaths Journal of African Theology 12: 88-101. 